\title{
Agronomic Performance, Variance Components, and Clustering in Vernonia galamensis Germplasm from Ethiopia
}

\author{
Alemneh Mideksa $\mathbb{D i}^{1,2}$ and Kassahun Tesfaye $\mathbb{D}^{2,3}$ \\ ${ }^{1}$ Department of Applied Biology, School of Natural Sciences, Adama Science and Technology University, P.O. Box 1888, \\ Addis Ababa, Ethiopia \\ ${ }^{2}$ Department of Microbial, Cellular and Molecular Biology, College of Natural Sciences, Addis Ababa University, P.O. Box 1176, \\ Addis Ababa, Ethiopia \\ ${ }^{3}$ Ethiopian Biotechnology Institute, Ministry of Science and Technology, P.O. Box 32853, Addis Ababa, Ethiopia
}

Correspondence should be addressed to Alemneh Mideksa; alemneh.mideksa@astu.edu.et

Received 20 August 2021; Accepted 3 January 2022; Published 1 February 2022

Academic Editor: Mehdi Rahimi

Copyright (c) 2022 Alemneh Mideksa and Kassahun Tesfaye. This is an open access article distributed under the Creative Commons Attribution License, which permits unrestricted use, distribution, and reproduction in any medium, provided the original work is properly cited.

\begin{abstract}
This study was conducted to assess the agronomic performance, variance components, and clustering analysis of 80 accessions of Vernonia galamensis, in alpha-lattice design with two replications at Melka Werer and Wondo Genet agricultural research centers in 2018/19. The one-way ANOVA showed that the high significant variation $(p<0.05)$ for most of the quantitative traits among accessions except for days to emergence, and the mean performance of seed yield per hectare ranged from 348.9 to $624.3 \mathrm{~kg} \mathrm{ha}^{-1}$, with an average of $474.4 \mathrm{~kg} \mathrm{ha}^{-1}$. The result of principal component analysis indicated that those exhibited more than one eigenvalue were about $71.0 \%$ of variability. While the cluster analysis based on $80 \%$ of similarity into eight clusters from the eighty accessions, the first cluster had the largest number of accessions. Overall, the study confirmed that the agromorphological characters such as the number of heads per plant, number of seeds per head, seed yield per plant, and seed weight per plot were the main contributors for seed yield per hectare in V. galamensis.
\end{abstract}

\section{Introduction}

Vernonia plant (Vernonia galamensis (Cass.) Less.; $2 n=18$ ), Asteraceae family [1-3], contains more than 500 species. It has two major centers of origin, South America and tropical Africa [4]. The greatest diversity of V. galamensis is found in East Africa, mainly in Ethiopia and Kenya [5]. Economically, it is used as a potential industrial crop due to a high sources of natural epoxidized oil (vernolic acid) [6] and other essential fatty acids such as linoleic acid, oleic acid, palmitic acid, stearic acid, and a trace amount of arachidic acid [7] rich in epoxidized fatty acid. It has a wide range uses in the production of oleochemicals such as paints, plastic formulations, and protective coatings [8].

Agronomic and morphological traits-based systems are the most common and easily observable markers, usually farmers and breeders use for classification and evaluation of yield or yield related traits. Furthermore, it provides good opportunity for effective selection and conservation measures [9]. In addition, there is a need to characterize the diverse genetic resources using different statistical tools and utilize them in the breeding programmes [10]. The process usually demands partitioning the overall variability of genotypes into its heritable and nonheritable components with the use of suitable genetic parameters such as genetic coefficient of variation, heritability, genetic advance, and multivariate analysis [11].

Production of V. galamensis may help as a source of raw material for agroprocessing industries and for its breeding researches. As a potential industrial plant, limited information is available and this plant considered only as a wild weed colonizing disturbed areas and bare agricultural lands [2]. Since, it is underutilized, and no much attention has been given to research and conservation of this plant. The 
species is also under threat of continued genetic erosion. Therefore, this study is so important including more accessions and testing at multiple locations to clearly understand the extents of the existing genetic variability for cultivation, proper conservation, and breeding programmes by using agronomic performance, variance components, and clustering analysis in V. galamensis.

\section{Materials and Methods}

2.1. Description of the Study Area. Eighty accessions of $V$. galamensis, which were collected from different regions in Ethiopia, were used as material in this study for agromorphological characterization. The field experiments were conducted at Melka Werer and Wondo Genet agricultural research centers from June to December, 2018.

2.2. Experimental Layout. The research was arranged in alpha-lattice design $(8 \times 10)$ with two replications. Each plot consisted of two rows of $2.5 \mathrm{~m}$ length with interspacing of $0.6 \mathrm{~m}$ and intraspacing of $0.6 \mathrm{~m}$, and the interblock spacing of $1.5 \mathrm{~m}$. Other cultural practices like cultivation and weeding control were done whenever needed. Five individual plants in the middle rows were tagged in each plot to avoid bordering effect and monitored until maturity. Agronomic characters such as days to emergence, days to $50 \%$ heading, days to $50 \%$ flowering, days to $90 \%$ maturity, plant height, branch number, branch length, number of heads per plant, number of seeds per head, seed yield per plant, 1000seed weight, seed weight per plot, and seed yield per hectare were evaluated.

2.3. Data Analysis. The analysis of variance (one-way ANOVA) was computed using the GraphPad Prism version 7.0 (GraphPad Software, Inc. California, San Diego) and SAS software. Principal component analysis and cluster analysis were performed using the MINITAB ${ }^{\circledR}$ version 17.1 (Minitab, 2013) software.

\section{Results}

3.1. Analysis of Variance and Mean Performance of Germplasm. The results of the analysis of variance (ANOVA) for all characteristics are shown in Table 1. The mean square revealed highly significant variation $(p<0.05)$ for most of the quantitative traits of accessions, except days to emergence. The accession by location interaction was also highly significant for all characteristics except days to emergence and thousand seed weight (Table 1). The performance of the agronomic traits in eighty $V$. galamensis accessions is presented in Table 2. The mean performance of seed yield ranged from $348.9 \mathrm{~kg} \mathrm{ha}^{-1}$ to $624.3 \mathrm{~kg} \mathrm{ha}^{-1}$ with an average of $474.4 \mathrm{~kg} \mathrm{ha}^{-1}$. The maximum length of $50 \%$ flowering was observed at 93.5 days at Melka Werer Agricultural Research Center (MWARC) and 111.5 days at Wondo Genet Agricultural Research Center (WGARC). Moreover, the earliest $50 \%$ heading was observed at 63.5 days, and the latest $50 \%$ heading was 73.0 days at MWARC whereas the earliest $50 \%$ heading was at 81.5 days, and the latest $50 \%$ heading was at 91.0 days at WGARC (Table 2).

3.2. Genetic Variability, Heritability, and Genetic Advance. Phenotypic, genotypic, and environmental variances were calculated for $V$. galamensis accessions (Table 3). The phenotypic coefficient of variation ranged from $11.5 \%$ (TSW) to $99.6 \%(\mathrm{BL})$, and the genotypic coefficient of variation ranged from $8.2 \%$ (TSW) to $95.4 \%$ (SWP). In the study, the heritability of the different traits were measured and ranged from 11.7 to $95.2 \%$ (Table 3). Moreover, the genetic advance as a percentage of mean ranged from $2.3 \%$ to $70.1 \%$, for days to $90 \%$ maturity and seed weight per plot, respectively. Relatively high heritability coupled with high genetic advance in percentage of the mean was recorded for a number of heads per plant and seed weight per plot (Table 3).

3.3. Principal Component Analysis. Principal component analysis (PCA) indicated that the first vectors were more important than the second and other vectors. In the principal component analysis, four principal components exhibited more than one eigenvalue and showed $71.0 \%$ of the variation (Table 4). The first PC accounted for $37.8 \%$ of the total variation, whereas the corresponding values for the second to the fourth PCs were $15.3 \%, 9.6 \%$, and $8.4 \%$, respectively. Traits such as days to $50 \%$ heading, days to $90 \%$ maturity, number of heads per plant, number of seeds per head, seed yield per hectare, and 1000-seed weight were indicated the major contributors for the variations in the first principal component (Table 4).

3.4. Cluster Analysis. The cluster analysis is based on $80 \%$ similarity of eighty accessions into eight clusters (Figure 1, Table 5). Cluster I had the largest number of accessions and characterized by relatively high seed yield per plant, seed weight per plot, and seed yield per hectare. Accessions in cluster II $(n=15)$ had the highest thousand seed weight. Cluster III had the sixteen accessions, characterized by the highest number of seeds per head. Cluster-IV $(n=6)$ is characterized by the highest number of branches. Cluster $\mathrm{V}$ ( $n=3$ accessions) was mainly distinguished by having the lowest value in thousand seed weight. Cluster VI had five accessions, characterized by the highest number of heads per plant and number of seeds per head. Cluster VII was comprised of twelve accessions and characterized with the highest number of days to $50 \%$ heading, plant height, days to $50 \%$ flowering, and thousand seed weight. Cluster VIII contained only two accessions and characterized by the highest branch length.

\section{Discussion}

Genetic diversity analysis of germplasm using agromorphological traits is an initial step for crop improvement. In line with this, 80 correctly stated $V$. galamensis were used for the agromorphological traits. The mean square showed 


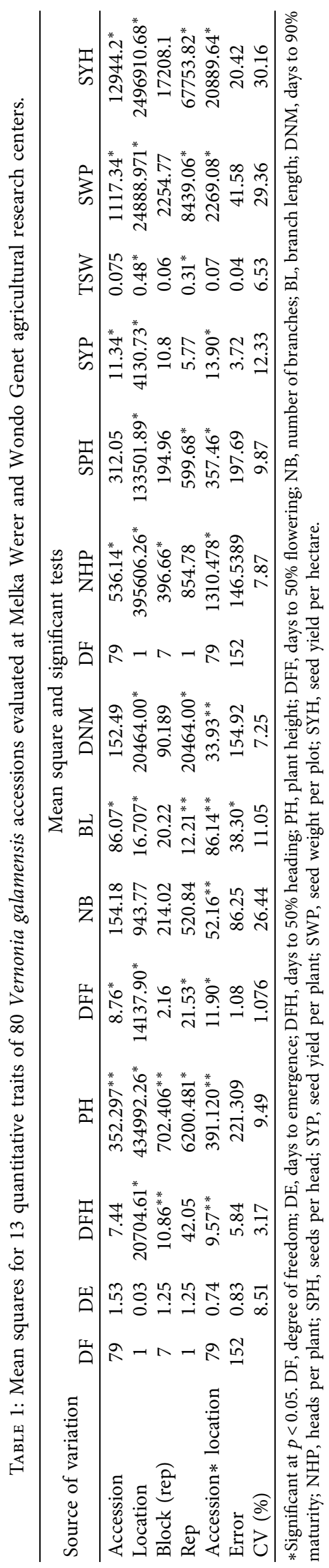


TABle 2: Estimates of mean performance and ranges for 13 quantitative traits of Vernonia galamensis grown at Melka Werer and Wondo Genet agricultural research centers.

\begin{tabular}{|c|c|c|c|c|c|c|}
\hline \multirow{3}{*}{ Quantitative traits } & \multicolumn{6}{|c|}{ Mean performance } \\
\hline & \multicolumn{3}{|c|}{ Melka Werer } & \multicolumn{3}{|c|}{ Wondo genet } \\
\hline & Mean & Minimum & Maximum & Mean & Minimum & Maximum \\
\hline Days to emergence & $10.74 \pm 0.1$ & 9.0 & 12.5 & $10.72 \pm 0.1$ & 9.5 & 13.0 \\
\hline Days to $50 \%$ heading & $68.13 \pm 0.3$ & 63.5 & 73.0 & $84.22 \pm 0.3$ & 81.5 & 91.0 \\
\hline Days to $50 \%$ flowering & $89.82 \pm 1.3$ & 85.0 & 93.5 & $103.11 \pm 1.7$ & 96.0 & 111.5 \\
\hline Plant height $(\mathrm{cm})$ & $119.88 \pm 0.3$ & 89.5 & 143.5 & $193.62 \pm 0.4$ & 159.5 & 228.0 \\
\hline Number of branches/plant & $33.41 \pm 0.9$ & 17.8 & 52.4 & $36.85 \pm 0.9$ & 19.5 & 59.5 \\
\hline Branch length $(\mathrm{cm})$ & $56.26 \pm 0.8$ & 46.0 & 71.9 & $72.81 \pm 0.8$ & 43.0 & 76.0 \\
\hline Days to $90 \%$ maturity & $163.65 \pm 0.9$ & 151.0 & 177.0 & $179.64 \pm 0.8$ & 165.5 & 198.5 \\
\hline Number of head/plant & $118.73 \pm 2.9$ & 84.9 & 188.4 & $189.06 \pm 2.2$ & 132.4 & 239.2 \\
\hline Number of seed/head & $121.99 \pm 1.8$ & 93.1 & 163.5 & $162.84 \pm 1.2$ & 141.2 & 189.0 \\
\hline Seed yield/plant (g) & $12.04 \pm 0.2$ & 8.7 & 16.8 & $19.22 \pm 0.3$ & 14.9 & 25.7 \\
\hline Seed weight/plot (g) & $113.74 \pm 39.5$ & 58.6 & 246.8 & $169.51 \pm 44.3$ & 116.8 & 331.2 \\
\hline 1000 -seed weight $(\mathrm{g})$ & $3.00 .00 \pm 0.0$ & 2.7 & 3.4 & $3.08 \pm 0.0$ & 2.4 & 3.5 \\
\hline Seed yield $\left(\mathrm{kg} \mathrm{ha}^{-1}\right)$ & $385.49 \pm 9.4$ & 246.8 & 822.7 & $562.16 \pm 11.5$ & 406.0 & 1104.0 \\
\hline
\end{tabular}

Significant at $p<0.05$.

TABLE 3: Estimates of mean, genotypic coefficient of variations (GCVs), phenotypic coefficient of variations (PCVs), heritability, and genetic advance as a percentage of the mean (GA\%) for 13 quantitative traits.

\begin{tabular}{lcccccccccc}
\hline Quantitative traits & Mean & $\mathrm{Vp}$ & $\mathrm{Vg}$ & $\mathrm{Ve}$ & PCV\% & GCV\% & ECV\% & $\mathrm{h}^{2} \mathrm{~B}$ & $\mathrm{GA}$ & $\mathrm{GAM}$ \\
\hline DE & 10.7 & 0.8 & 0.4 & 0.4 & 28.0 & 19.8 & 3.9 & 50.3 & 1.1 \\
DFH & 76.2 & 5.7 & 2.8 & 2.9 & 27.3 & 19.0 & 3.8 & 48.6 & 8.6 & 11.3 \\
DFF & 96.5 & 10.5 & 10.0 & 0.6 & 33.1 & 32.2 & 1.6 & 94.8 & 14.3 & 14.8 \\
PH & 156.8 & 90.3 & 69.9 & 20.4 & 75.9 & 66.8 & 13.0 & 77.4 & 65.6 & 41.9 \\
NB & 35.1 & 12.3 & 8.1 & 4.2 & 59.2 & 48.0 & 12.1 & 65.6 & 15.1 & 42.9 \\
BL & 64.5 & 55.5 & 36.3 & 17.1 & 99.5 & 80.5 & 26.5 & 65.4 & 11.1 & 19.8 \\
DNM & 171.7 & 87.7 & 10.3 & 77.5 & 71.5 & 24.4 & 45.1 & 11.7 & 3.9 & 2.3 \\
NHP & 153.9 & 108.1 & 94.8 & 13.3 & 83.8 & 78.5 & 8.6 & 87.7 & 78.1 & 50.7 \\
SPH & 142.4 & 106.0 & 57.2 & 98.9 & 86.3 & 63.3 & 64.4 & 53.9 & 29.5 \\
SWP & 141.6 & 135.5 & 129.0 & 106.5 & 97.8 & 95.4 & 75.2 & 95.2 & 99.3 & 70.1 \\
SYP & 15.6 & 5.8 & 3.9 & 1.9 & 60.7 & 49.9 & 11.9 & 67.7 & 6.4 & 41.2 \\
SYH & 473.8 & 313.4 & 227.2 & 86.2 & 81.3 & 69.2 & 18.2 & 72.5 & 95.9 & 20.2 \\
TSW & 3.0 & 0.0 & 0.0 & 0.0 & 11.5 & 8.1 & 2.7 & 50.0 & 0.3 & 8.3 \\
\hline
\end{tabular}

$\mathrm{DE}$, days to emergence; $\mathrm{DFH}$, days to $50 \%$ heading; $\mathrm{PH}$, plant height; DFF, days to $50 \%$ flowering; NB, number of branches; BL, branch length; DNM, days to 90\% maturity; NHP, number of heads per plant; SPH, number of seeds per head; SYP, seed yield per plant; SWP, seed weight per plot; SYH, seed yield per hectare; TSW, 1000-seed weight; Vg, genotypic variation; Vp, phenotypic variation; Ve, environmental variation; GCV, genotypic coefficient of variation; PCV, phenotypic coefficient of variation; GA, genetic advance; GAM, genetic advance as percentage of mean at $5 \%$ selection intensity.

TABle 4: Principal component analysis for 13 quantitative traits of 80 Vernonia galamensis accessions.

\begin{tabular}{lcccc}
\hline Variables & PC1 & PC2 & PC3 & PC4 \\
\hline Days to emergence & 0.03 & -0.11 & 0.60 & 0.33 \\
Days to 50\% heading & 0.93 & -0.18 & -0.10 & 0.04 \\
Plant height (cm) & 0.90 & -0.07 & -0.06 & 0.12 \\
Days to 50\% flowering & 0.90 & -0.18 & -0.11 & 0.08 \\
Number of branches/plant & 0.24 & -0.22 & 0.56 & -0.33 \\
Branch length (cm) & -0.02 & 0.45 & 0.17 & 0.73 \\
Days to 90\% maturity & 0.61 & -0.34 & 0.27 & -0.15 \\
Number of head/plant & 0.82 & -0.08 & -0.05 & 0.11 \\
Number of seed/head & 0.80 & -0.02 & -0.23 & 0.12 \\
Seed yield/plant (g) & 0.79 & -0.14 & -0.16 & 0.16 \\
Seed weight/plot (g) & 0.70 & 0.61 & 0.14 & -0.27 \\
Seed yield (kg ha $\left.{ }^{-1}\right)$ & 0.69 & 0.63 & 0.13 & -0.27 \\
1000-seed weight (g) & 0.21 & -0.08 & 0.45 & 0.11 \\
Eigenvalue & 5.86 & 1.25 & 1.11 & 1.01 \\
Proportion & 0.38 & 0.15 & 0.10 & 0.08 \\
Cumulative & 0.38 & 0.53 & 0.63 & 0.71 \\
\hline
\end{tabular}

highly significant variation for most of the quantitative traits such as the number of heads per plant, number of seeds per head, and seed yield. These variations among accessions would provide a good opportunity for improvement through the selection of the cultivated plant. This finding is consistent with the previous report Baye et al. [5] and Shimelis et al. [12].

The mean performance showed significant differences among seed yield and yield components. For example, five quantitative traits including number of heads per plant, number of seeds per head, seed yield per plant, seed weight per plot, and seed yield per hectare showed three times more performances compared to minimum mean performance range. Such significant and wide range of genetic variation indicates that the existence of large genetic variability among the tested accessions and extrapolation to the crop as a whole could be used as a fundamental information for further work in cultivation, conservation, and breeding. Baye et al. [5], 


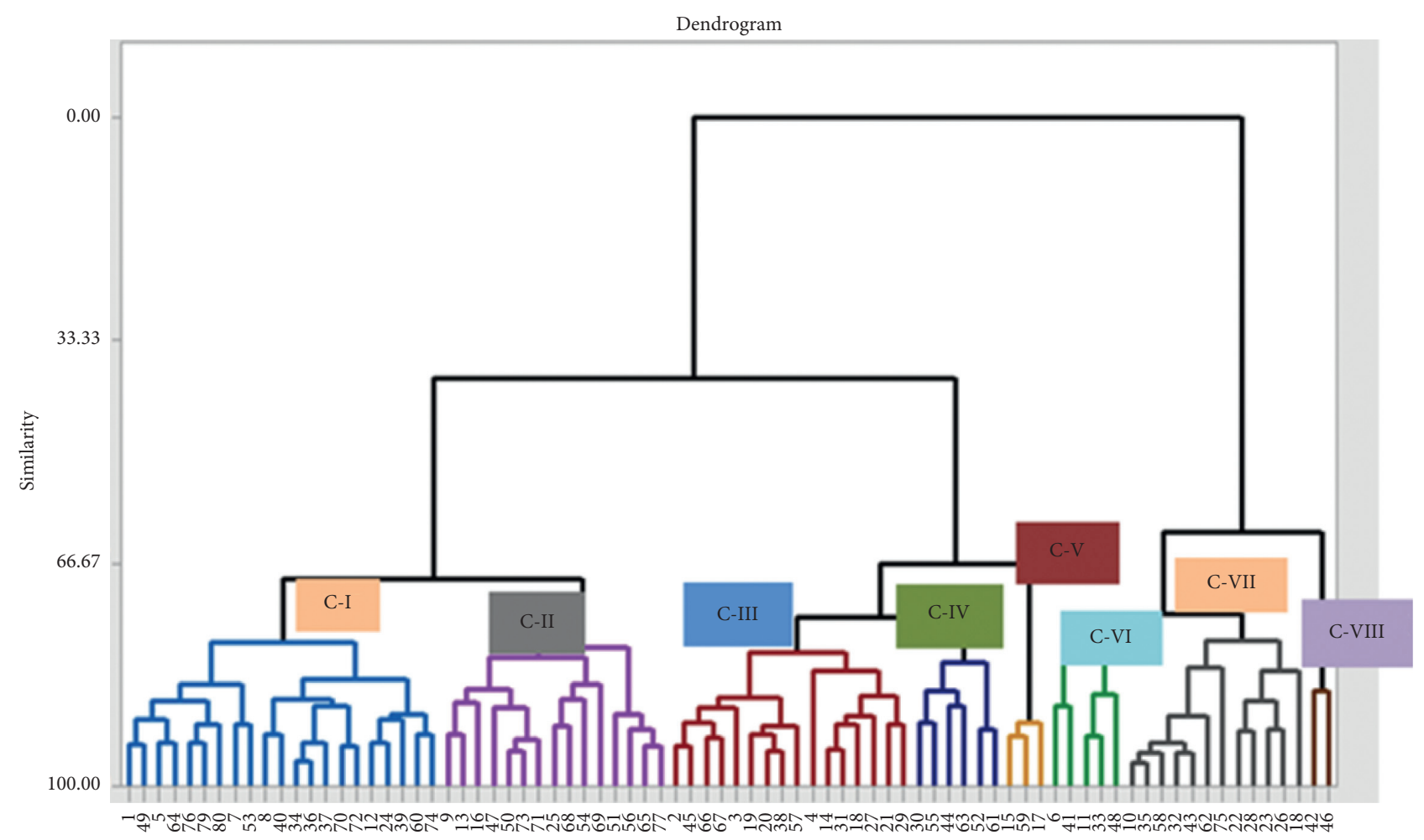

Figure 1: Dendrogram from cluster analysis of eighty accessions of Vernonia galamensis.

TABle 5: Mean values of 13 quantitative traits used in the clusters of 80 Vernonia galamensis accessions.

\begin{tabular}{lccccccc}
\hline & & \multicolumn{3}{c}{ Cluster } & & \\
& I & II & III & IV & V & VI & VII \\
\hline DE & 10.25 & 10.94 & 10.41 & 10.67 & 10.84 & 10.38 & 11.17 \\
DFH & 75.50 & 76.17 & 75.72 & 76.08 & 76.17 & 76.13 & 77.92 \\
PH & 158.47 & 157.78 & 152.48 & 159.79 & 157.55 & 158.00 & 161.52 \\
DFF & 81.41 & 81.63 & 79.53 & 82.18 & 81.52 & 81.50 & 83.53 \\
NB & 36.75 & 32.55 & 29.12 & 41.68 & 36.34 & 36.09 & 32.20 \\
BL & 54.19 & 56.65 & 55.52 & 55.23 & 54.70 & 56.66 & 54.27 \\
DNM & 172.00 & 173.08 & 169.52 & 176.46 & 170.23 & 165.13 & 174.25 \\
NHP & 154.67 & 143.73 & 149.21 & 173.00 & 153.26 & 176.08 & 143.83 \\
SPH & 139.59 & 141.48 & 145.28 & 133.09 & 140.82 & 153.79 & 138.23 \\
SYP & 16.26 & 15.15 & 15.76 & 15.72 & 15.49 & 16.01 & 17.94 \\
SWP & 173.99 & 160.45 & 123.29 & 124.49 & 137.72 & 158.36 & 150.37 \\
SYH & 607.75 & 533.10 & 411.89 & 396.14 & 462.10 & 560.32 & 107.69 \\
TSW & 3.03 & 3.05 & 3.03 & 3.01 & 2.89 & 2.98 & 145.13 \\
\hline
\end{tabular}

DE, days to emergence; DFH, days to $50 \%$ heading; PH, plant height; DFF, days to $50 \%$ flowering; NB, number of branches; BL, branch length; DNM, days to $90 \%$ maturity; NHP, heads per plant; SPH, seeds per head; SYP, seed yield per plant; SWP, seed weight per plot; SYH, seed yield per hectare; TSW, 1000-seed weight.

Shimelis et al. [12], and Mebrahtu et al. [13] reported a similar results with slight differences in the magnitude which could be attributed to differences in the number of samples studied and experimental sites used. In addition, the average seed yield per hectare $\left(473.82 \pm 20.42 \mathrm{~kg} \mathrm{ha}^{-1}\right)$ was comparable with the result of Mebrahtu et al. [13] and slightly lower than with the results of Baye et al. [2] and Shimelis et al. [12].

Phenotypic coefficient of variation (PCV) was observed higher than their corresponding genotypic coefficient of variation (GCV) for all the characters and had environmental effects on all the traits. According to Jakhar et al. [14] and Bhargav et al. [15], the PCV and GCV values greater than $20 \%$ are considered as high, values between 10 and $20 \%$ are considered as medium, and less than $10 \%$ are classified as low. Therefore, according to the classification, high PCV and GCV values were recorded for number of branches, days to $90 \%$ maturity, number of heads per plant, number of seeds per head, and seed yield per hectare, suggest the possibility of improving these traits through selection. On the other hand, it is estimated that GCV and PCV were low in the study for thousand seed weight (11.51\% and $8.14 \%$, respectively). Baye et al. [16] reported that the phenotypic and genotypic variation were closer to each other for most of the characters; however, the magnitude of the environmental variation was 
relatively lower than the genotypic variation for most characters except days to $90 \%$ maturity and number of seeds per head.

In the study, the heritability of the different traits ranged from 11.69 to $95.22 \%$. High heritability does not always indicate a high genetic gain; however, heritability with genetic advance as a percentage of mean should be considered in predicting the ultimate effect of selecting superior varieties. The genetic advance as a percentage of mean ranged from 2.3 to $70.13 \%$ for days to maturity, and seed weight per plot, respectively. Relatively high heritability coupled with high genetic advance as percentage of the mean was recorded for a number of heads per plant and seed weight per plot, indicating that selection for the stated characters could be more effective due to additive gene action. Johnson et al. [17] reported that high heritability coupled with high GAM is usually more helpful in predicting gain under selection than heritability alone. Rosielle and Hamblin [18] reported that heritability and genetic advance values may be concealed due to a greater genotype by environment under unfavorable condition. Ceccarelli [19] on the contrary reported that there is no interrelationship between the type of the environment and the magnitude of heritability and genetic advance values.

Principal component analysis (PCA) indicated that four principal components exhibited more than one eigenvalue and showed $71.0 \%$ of the variation. The eigenvalues above 1 indicate the evaluated principle component weight values are reliable. Traits such as days to $50 \%$ heading, days to $90 \%$ maturity, number of heads per plant, number of seeds per head, seed yield per hectare, and 1000-seed weight were the major contributors for the variations observed in the first principal component. Similar observations were found by researchers [20-24].

Clustering was done based on the mean values of the agromorphological traits, and $65 \%$ of the accessions were grouped under the first three clusters, indicating the existence of considerable differences in the mean values of different traits. Accessions falling under clusters 1, 2, 3, and 7 had a maximum mean performance in traits such as seed yield per plant, seed yield per hectare, number of seeds per head, and number of heads per plant. Moreover, the mean based clustering pattern indicates a wide diversity of accessions between different groups and their close relationship within a cluster. It is, therefore, logical to expect a higher genetic diversity from accessions of different clusters than within a cluster, which is also important in breeding and parental selection [25].

\section{Conclusion}

The study revealed that there were significant genetic variabilities for all the quantitative traits $(p<0.05)$, except days to emergence among $V$. galamensis accessions. Seed yield was positively and significantly associated with the number of heads per plant, number of seeds per head, and seed yield per plant, indicating the importance of these traits for seed yield improvement studies. The magnitude of phenotypic coefficient of variation was higher than their corresponding genotypic coefficient of variation for all the characters, suggesting the presence of environmental influence on all the traits studied. Relatively high heritability coupled with high genetic advance as percentage of the mean was recorded for the number of heads per plant and seed weight per plot, indicating that selection for these characters could be more effective. In addition, four principal components with $71.0 \%$ of the variation and eight clusters were observed. Generally, the study revealed that the existence of variabilities in Vernonia galamensis plant. Most of the values of variability detected are important as fundamental information for future V. galamensis cultivation, breeding, and conservation in Ethiopia. In addition, breeding studies of this plant should be supported by advanced genetic engineering technology.

\section{Data Availability}

The dataset that supports the findings in the study is available from the corresponding author upon request.

\section{Conflicts of Interest}

The authors declare that they have no conflicts of interest.

\section{Authors' Contributions}

$\mathrm{AM}$ and $\mathrm{KT}$ designed the study. In addition, KT supported the field work, and AM performed the statistical data analysis and wrote the manuscript. All the authors read and approved the final manuscript.

\section{Acknowledgments}

The authors wish to thank the Melka Werer and Wondo Genet agricultural research centers and Adama Science and Technology University for creating good working environment during the research period.

\section{References}

[1] A. E. Thompson, D. A. Dierig, E. R. Johnson, G. H. Dahlquist, and R. Kleiman, "Germplasm development of Vernonia galamensis as a new industrial oilseed crop," Industrial Crops and Products, vol. 3, no. 3, pp. 185-200, 1994.

[2] T. Baye, "Genotypic and phenotypic variability in Vernonia galamensis germplasm collected from eastern Ethiopia," The Journal of Agricultural Science, vol. 139, no. 2, pp. 161-168, 2002.

[3] H. Shimelis and A. Hugo, "Determination of selection criteria for seed yield and seed oil content in Vernonia (Vernonia galamensis variety ethiopica)," Industrial Crops and Products, vol. 33, no. 2, pp. 436-439, 2011.

[4] A. E. Thompson, D. A. Dierig, and R. Kleiman, "Variation in Vernonia galamensis flowering characteristics, seed oil and vernolic acid contents," Industrial Crops and Products, vol. 3, no. 3, pp. 175-183, 1994.

[5] T. Baye, H. Kebede, and K. Belete, "Agronomic evaluation of Vernonia galamensis germplasm collected from eastern Ethiopia," Industrial Crops and Products, vol. 14, no. 3, pp. 179-190, 2001.

[6] T. Baye, H. C. Becker, and S. V. Witzke-Ehbrecht, "Vernonia galamensis, a natural source of epoxy oil: variation in fatty 
acid composition of seed and leaf lipids," Industrial Crops and Products, vol. 21, pp. 257-261, 2005.

[7] A. E. Thompson, D. A. Dierig, and R. Kleiman, "Characterization of Vernonia galamensis germplasm for seed oil content, fatty acid composition, seed weight, and chromosome number," Industrial Crops and Products, vol. 2, pp. 299-305, 1994.

[8] D. Mills, "Response ofVernonia galamensisgrown in the greenhouse to liquid fertilization," Journal of Plant Nutrition, vol. 22, no. 11, pp. 1665-1678, 1999.

[9] M. Govindaraj, M. Vetriventhan, and M. Srinivasan, "Importance of genetic diversity assessment in crop plants and its recent advances: an overview of its analytical perspectives," Genetics Research International, vol. 2015, Article ID 431487, 14 pages, 2015.

[10] G. Burow, C. D. Franks, Z. Xin, and J. J. Burke, "Genetic diversity in a collection of Chinese sorghum landraces assessed by microsatellites," Americal Journal of Plant Sciences, vol. 3, p. 12, 2012.

[11] H. A. Shimelis, P. W. Mashela, and A. Hugo, "Principal agronomic and seed oil traits in the industrial oil crop vernonia (Centrapalus pauciflorus var. ethiopica)," South African Journal of Plant and Soil, vol. 30, pp. 131-137, 2013.

[12] H. Shimelis, P. W. Mashela, and A. Hugo, "Performance of vernonia as an alternative industrial oil crop in limpopo province of South Africa," Crop Science, vol. 48, no. 1, pp. 236-242, 2008.

[13] T. Mebrahtu, T. Gebremariam, A. Kidane, and W. Araia, "Performance of Vernonia galamensis as a potential and viable industrial oil plant in Eritrea: yield and oil content," African Journal of Biotechnology, vol. 8, pp. 635-640, 2009.

[14] D. S. Jakhar, M. S. Kamble, A. Singh, and P. Raj, "Genetic variability, character association and path coefficient analysis in Chickpea (Cicer arietinum L.). Ecology," Environmental Conservation, vol. 22, pp. 239-244, 2016.

[15] V. Bhargav, R. Kumar, T. M. Rao, and T. U. Bharathi, "Genetic variability, character association and path coefficient analysis in China aster (Callistephus chinensis)," Indian Journal of Agricultural Sciences, vol. 89, pp. 1643-1648, 2018.

[16] T. Baye and H. C. Becker, "Genetic variability and interrelationship of traits in the industrial oil crop Vernonia galamensis," Euphytica, vol. 142, pp. 119-129, 2005.

[17] H. W. Johnson, H. F. Robinson, and R. E. Comstock, "Estimates of genetic and environmental variability in soybeans," Agronomy Journal, vol. 47, pp. 314-318, 1995.

[18] A. A. Rosielle and J. Hamblin, "Theoretical aspects of selection for yield in stress and non-stress environment," Crop Science, vol. 21, pp. 943-946, 1981.

[19] S. Ceccarelli, "Specific adaptation and breeding for marginal conditions," Euphytica, vol. 77, no. 3, pp. 205-219, 1994.

[20] E. P. Smith, "Methods of multivariate analysis," Journal of Statistical Planning and Inference, vol. 59, 1997.

[21] A. C. Rencher: Principal Component Analysis. Methods of Multivariate Analysis, 2012.

[22] M. J. Anderson, "A new method for non-parametric multivariate analysis of variance," Austral Ecology, vol. 26, no. 1, pp. 32-46, 2008.

[23] A. C. Rencher: A Review of "Methods of Multivariate Analysis, 2005.

[24] B. Everitt and A. C. Rencher, "Methods of multivariate analysis," Statistics, vol. 45, 1996.

[25] D. S. Falconer, "Introduction to quantitative genetics," Population, vol. 17, pp. 152-153, 1962. 